\title{
The international global navigation satellite systems service (IGS): development and achievements
}

\author{
Gerhard Beutler • Angelyn W. Moore • \\ Ivan I. Mueller
}

\begin{abstract}
Since 21 June 1992 the International GPS Service (IGS), renamed International GNSS Service in 2005, produces and makes available uninterrupted time series of its products, in particular GPS observations from the IGS Global Network, GPS orbits, Earth orientation parameters (components $x$ and $y$ of polar motion, length of day) with daily time resolution, satellite and receiver clock information for each day with different latencies and accuracies, and station coordinates and velocities in weekly batches for further analysis by the IERS (International Earth Rotation and Reference Systems Service). At a later stage the IGS started exploiting its network for atmosphere monitoring, in particular for ionosphere mapping, for troposphere monitoring, and time and frequency transfer. This is why new IGS products encompass ionosphere maps and tropospheric zenith delays. This development became even more important when more and more space-missions carrying space-borne GPS for various purposes were launched. This article offers an overview for the broader scientific community of the development of the IGS and of the spectrum of topics addressed today with IGS data and products.
\end{abstract}

G. Beutler $(\varangle)$

Astronomical Institute, University of Bern, Sidlerstrasse 5, 3012 Bern, Switzerland

e-mail: gerhard.beutler@aiub.unibe.ch

\begin{abstract}
A. W. Moore
Jet Propulsion Laboratory, California Institute of Technology, 4800 Oak Grove Drive, MS 238-540, Pasadena, CA 91109, USA e-mail: awmoore@mail.jpl.nasa.gov
\end{abstract}

\section{I. Mueller}

Department of Geodetic Science,

The Ohio State University, 4361 Shire Creek Court,

Hilliard, OH 43026, USA

e-mail: mueller.3@osu.edu
Keywords Global positioning system (GPS) . Global navigation satellite systems (GNSS) . Orbit determination · International GNSS service

\section{Introduction}

Since early 1994 the U.S. Global positioning system (GPS) is fully operational. The constellation consists nominally of 24 , de facto of about 30, active satellites. In January 2008, 31 GPS satellites were orbiting the Earth about 20,000 km above the Earth's surface, in six orbital planes, which are inclined by 55 degrees with respect to the equatorial plane and separated by 60 degrees in the equator. GLONASS (Global Navigation Satellite System) is the Russian counterpart of the GPS. In January 2008, 15 satellites were orbiting the Earth about 19,000 km above the Earth surface, distributed in three orbital planes with 63 degrees inclination with respect to the equatorial plane, and separated by 120 degrees at the equator. The European GALILEO system is under development. Currently one test satellite, GIOVE-A, is orbiting the Earth. GPS, GLONASS, and GALILEO are designed as Global Navigation Satellite Systems (GNSS) offering 24h weather-independent positioning services, which are based on the following principles:

- The heart of each GNSS spacecraft is a high-quality oscillator, which is used to generate at least two coherent carriers in the microwave $L$-band allowing it to eliminate (or greatly reduce) the influence of ionospheric refraction.

- The satellites transmit information using the phase modulation technique, in particular so-called "codes", about the current satellite position and velocity (broadcast ephemeris information) and the satellite clock errors with respect to a system time. 
- The GNSS receivers have omni-directional antennas allowing them to receive the signals of all satellites in view of the antenna, either of one particular system (e.g., GPS or GLONASS receivers) or all available systems (combined GNSS receivers).

- The broadcast codes and the satellite ephemerides allow receivers on Earth or in the Earth-near space to determine their position instantaneously (in real-time) in a welldefined, openly accessible global reference frame with meter level precision.

- The real-time (or navigation) task is the primary task of all GNSS.

Instead of using the transmitted codes as primary observable it is also possible to analyze the carrier phases themselves. As the phases can be resolved within small fractions of the wavelength, the transition from "code" to "phase" is associated with a gain in accuracy of about a factor of 1,000 , allowing positioning with $\mathrm{cm}$ to $\mathrm{mm}$ precision. Sophisticated analysis tools (software) and much better knowledge of the satellite clock corrections and ephemerides are required, however. The satellite positions have to be known with (few) $\mathrm{cm}$ accuracy, and the satellite clock corrections within few picoseconds (ps) $\left(1 \mathrm{ps}=10^{-12} \mathrm{~s}\right)$.

Exploiting the GNSS in this advanced sense to the benefit of science and society in general is the main goal of the IGS, the International GNSS Service, which was called International GPS Service prior to the year 2005.

\section{The pre-IGS period}

The efficiency of international cooperation in geodetic GPS was already demonstrated in the early years prior to the completion of the constellation. In 1984 a campaign placed five receivers at eight VLBI (Very Long Baselines Interferometry) sites in Alaska (USA) and the Yukon and Northwest Territories of Canada. The Swiss and U.S. team that processed the data (Beutler et al. 1987) acknowledged that the measurements were made possible by the cooperation of the Defense Mapping Agency and the Applied Research Laboratory of the University of Texas in the U.S. with the Earth Physics Branch of the Department of Energy, Mines and Resources (EMR) in Canada.

In 1988 an ambitious experiment placed 43 receivers at 47 sites in Central and South America (hence the project name, CASA UNO) as well as 13 "extended fiducial tracking" sites spanning 220 degrees of longitude and 125 degrees of latitude from Australia to Scandinavia. At the time, a TI4100 station cost approximately US\$150,000, making the economic efficiency of sharing resources trivially evident. This project also debuted the "new" ROGUE field receivers and the now familiar choke-ring antenna designed to minimize multipath for geodetic applications (Neilan et al. 1989). This ambitious campaign included 34 collaborating agencies in 12 countries.

The first GPS IERS (International Earth Rotation and Reference Systems Service) and Geodynamics Experiment1991 ("GIG '91") experiment was another important definedduration campaign that proved the value of global GPS networks to geodesy (Melbourne et al. 1993). Seventy agencies deployed 120 receivers to assess the utility of GPS together with other space geodetic techniques in the IERS' Earth orientation monitoring and terrestrial reference frame determination. The GIG '91 time series was the first GPS dataset to be used in a realization of the International Terrestrial Reference Frame (ITRF), specifically ITRF91 (Boucher and Altamimi 1993).

By now it was clear that GPS would have a profound impact on geodesy and geodynamics, and that a civilian reference network was needed to monitor the constellation and the surface of the Earth, so that individual regional studies would not each require deployment of a large-scale reference network outside the region of interest. These projects demonstrated multiple efficiencies (financial, logistical, effort) in combining individual agencies' resources to realize a cooperative, enduring infrastructure that would ensure worldwide availability of global GPS data and products for geodetic use. More information concerning the pre-IGS period may be found in Moore (2007).

\section{The IGS development in overview}

The initial development of the IGS consisted of a planning phase between 1989 and 1991 initiated by Ivan I. Mueller, a proof of concept phase for this scientific service with the 1992 IGS Test Campaign and the densification experiment called Epoch'92, then a continuation of activities after the official end of the 1992 campaign in the form of the so-called IGS Pilot Service. The official service started on 1 January 1994. The planning phase of the IGS is covered by Mueller (1990, 1992a,b), the proof of concept phase by Mueller (1993a,b,c,d) and Beutler et al. (1994, 1996).

In the second half of the 1990s the IGS developed into an interdisciplinary service in support of Earth sciences and fundamental astronomy, including significant contributions to the ITRF and Earth rotation parameters. Global ionosphere maps could be generated and tropospheric refraction above the IGS tracking sites could be monitored (Beutler et al. 1999).

Accurate time and frequency transfer between the timing laboratories was another topic covered within the IGS. Already in the late 1990s, the IGS extended its activities towards a general GNSS service by organizing the global tracking of the GLONASS. The orbits of all active 
GLONASS satellites became part of the IGS products in 2004.

\section{The IGS planning committee 1989-1991}

According to Mueller (1992a) the primary motivation in planning the IGS was the recognition in 1989 that the most demanding users of the GPS satellites, the geophysical community, were purchasing receivers in exceedingly large numbers and using them as more or less black boxes, using software packages which they did not completely understand, mainly for relative positioning. The observations as well as the subsequent data analyses were not based on common standards; thus the geodynamic interpretation of the results could not be trusted. The other motivation was the generation of precise ephemerides for the satellites together with by-products such as Earth orientation parameters and GPS clock information.

These ideas were first discussed in 1989 at the IAG General Meeting in Edinburgh by Neilan et al. (1990) and led soon thereafter to a Working Group, later designated as the IAG (International Association of Geodesy) Planning Committee for the IGS, with Ivan I. Mueller, then President of the IAG, as chairman. After several meetings the Call for Participation was issued on 1 February 1991. More than 100 scientific organizations and governmental survey institutions announced their participation either as an observatory (part of the IGS network), as an analysis center, or as a data center. The Jet Propulsion Laboratory (JPL) offered to serve as the Central Bureau, and The Ohio State University as the Analysis Center Coordinator. At the 20th General Assembly of the IUGG (International Union of Geodesy and Geophysics) in Vienna, August 1991, the IAG Planning Committee was restructured and renamed the IGS Campaign Oversight
Committee. Gerhard Beutler was asked to chair the committee, which organized the 1992 events, namely the 1992 IGS Test Campaign and Epoch'92. Two IGS Workshops (the first at the Goddard Space Flight Center in October 1991, the second in Columbus, Ohio in March 1992) were necessary to organize the 1992 activities. The essential events of this first phase of the IGS development are summarized in Table 1.

\section{The I992 IGS Test Campaign, Epoch'92, the IGS Pilot Service, and the 1993 IGS Workshop in Bern}

The 1992 IGS Test Campaign, scheduled to last from 21 June to 23 September 1992, focused on the routine determination of high accuracy orbits and Earth Rotation Parameters (ERPs). It was to serve as the proof of concept for the future IGS. Epoch'92, on the other hand, was scheduled as a 2-week campaign in the middle of the 3-month IGS Campaign for the purpose of serving as a first extension of the relatively sparse IGS Core Network analyzed on a daily basis by the IGS Analysis Centers. More background information about this early phase of IGS may be found in Mueller (1992a) and Mueller and Beutler (1992). Two events prior to the 1992 IGS Test campaign were crucial for the success of the 1992 IGS test campaign:

- the communications test, organized by Peter Morgan, Australia, demonstrated that data transmission using the scientific Internet facility had sufficient capacity for the daily data transfer from the IGS stations to the Regional, Operational and Global Data Centers and then to the Analysis Centers.

- The establishment of the IGS Mailbox and the IGS Report series based on e-mail proved to be very important
Table 1 Chronicle of events 1989-1991

\begin{tabular}{|c|c|}
\hline Date & Event \\
\hline August 1989 & $\begin{array}{l}\text { IAG Scientific Assembly in Edinburgh. Plans by Mueller, Mader, Melbourne, Minster, } \\
\text { and Neilan }\end{array}$ \\
\hline March 1990 & $\begin{array}{l}\text { IAG Executive Committee Meeting in Paris decides to establish a Working Group to } \\
\text { explore the feasibility of an IGS under IAG auspices. I.I. Mueller was elected as chairman }\end{array}$ \\
\hline April 1990 & The Working Group is designated as IAG Planning Committee for the IGS in Paris \\
\hline September 1990 & Planning Committee Meeting in Ottawa. Preparation of the Call for Participation (CFP) \\
\hline February 1991 & CFP mailed. Letters of Intent due 1 April 1991 \\
\hline April 1991 & CFP Attachments mailed to those whose letters of intent were received \\
\hline May 1991 & Proposals due \\
\hline June 1991 & Proposals evaluated and accepted in Columbus, Ohio \\
\hline August 1991 & $\begin{array}{l}\text { Planning Committee reorganized and renamed as IGS Campaign Oversight Committee } \\
\text { at the 20th IUGG General Assembly in Vienna }\end{array}$ \\
\hline October 1991 & First IGS Campaign Oversight Committee Meeting in Greenbelt, Maryland \\
\hline
\end{tabular}


Table 2 Chronicle of events 1991-1993

\begin{tabular}{ll}
\hline Date & Event \\
\hline March 1992 & 2nd IGS Oversight Committee Meeting at OSU, Columbus, OH, USA \\
May 1992 & Communication test \\
May 1992 & Establishment of IGS Mailbox at University of Bern \\
June 1992 & June 21: Start of IGS Test Campaign 1992 \\
July 1992 & First results \\
July 1992 & July 27: Start of Epoch'92 campaign, lasting for 2 weeks \\
September 1992 & September 23: Official end of the campaign, continuation on best effort basis \\
November 1992 & Start of IGS Pilot Service \\
March 1993 & March 25-26: 1st IGS Workshop in Bern, IGS Terms of Reference drafted \\
May 1993 & Meeting of the IGS Oversight Committee in Baltimore, USA \\
August 1993 & IAG Approval for IGS at IAG Scientific Meeting in Beijing \\
October 1993 & 12-14 October 1993: IGS Analysis Center Workshop, Ottawa, Canada \\
October 1993 & 18-19 October 1993: IGS Network Operations Workshop and First Governing Board \\
Mecember 1993 & 2nd Governing Board Meeting in San Francisco \\
\hline
\end{tabular}

as information resources and as a tool to ensure a close cooperation between the IGS participants. This e-mail service, initially located at the University of Bern and set up by Werner Gurtner, was transferred to the Central Bureau (JPL) by 1 January 1994.

The 1992 IGS Campaign started as scheduled on 21 June 1992. About 2 weeks later the first results of the IGS Analysis Centers started to flow into the IGS Global Data Centers, which in turn made these results available to the user community. The ERP series were regularly analyzed by the IERS Central Bureau and by the IERS Rapid Service Sub-bureau (as it was called at that time). Toward the end of the 1992 IGS Test Campaign it became clear that the campaign was a complete success and that it would be a mistake to stop or interrupt IGS data collection and analysis activities. Therefore, these activities continued on a best effort basis after the official end of the 1992 IGS Test Campaign on 23 September 1992.

At the third IGS Campaign Oversight Committee meeting on 15 October 1992 at Goddard Space Flight Center (see Table 2) it was decided to formally establish the IGS Pilot Service to bridge the gap between the 1992 IGS Test Campaign and the start of the official service. Since 1 November 1992 the orbits of the individual processing centers were regularly compared by the IGS Analysis Center Coordinator. An overview of the 1992 IGS events may also be found in the proceedings of the 1993 IGS Workshop, see (Beutler and Brockmann 1993). At the 1993 IGS Workshop in Bern, where the 1992 IGS Test Campaign and Epoch'92 were evaluated, "everybody" was confident that the IGS community was ready to start with the official service in the near future.
Table 3, showing the root-mean-square errors of the sevenparameter Helmert transformations between pairs of solutions (satellite positions at 15-min intervals of all active GPS satellites) indicates that the community was not only confident, but also very optimistic in 1993. When looking at the 1993 results with a smile from today's perspective one should, however, be aware of the fact that the generation of global geodetic products was based on a rather sparse global network in 1993 (see Fig. 1) and on rather recent software developments - the "analysis noise" was considerable in 1993.

Two Workshops, the Analysis Center Workshop in Ottawa (Kouba 1993) and the Network Operations Workshop in Silver Spring, MD, and the first Governing Board Meeting (also in Silver Spring) took place in October 1993. One important outcome of IGS meetings in October 1993 was the decision to produce an official IGS orbit. This responsibility was given to the IGS Analysis Center Coordinator, who, according to the IGS Terms of Reference must be an analysis center's representative. Jan Kouba was elected by the

Table 3 Mean values of root-mean-square errors in $\mathrm{cm}$ of seven-parameter Helmert transformations between pairs of orbital ephemerides as produced by the IGS Analysis Centers between 1 November 1992 and 15 November 1993, from (Beutler and Brockmann 1993)

\begin{tabular}{llllll}
\hline & COD & SIO & JPL & EMR & ESA \\
\hline COD & - & 43 & 46 & 38 & 87 \\
SIO & - & - & 48 & 39 & 81 \\
JPL & - & - & - & 33 & 75 \\
EMR & - & - & - & - & 87 \\
\hline
\end{tabular}


Fig. 1 The IGS Global Tracking Network in 1993

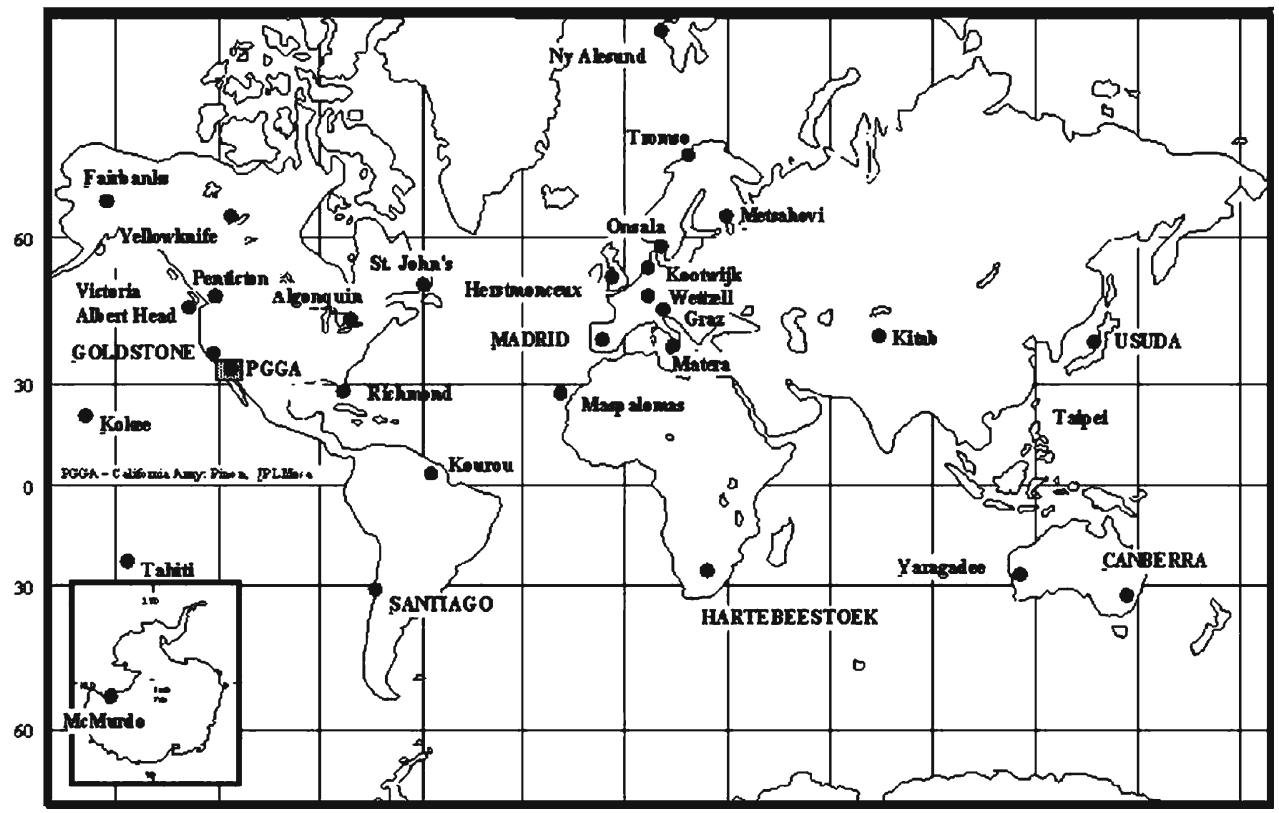

IGS Governing Board as the second Analysis Coordinator, Gerhard Beutler as the first Chair of the IGS Governing Board.

\section{The International GPS/GNSS Service 1994-present}

The IGS started its operations as an official IAG Service on 1 January 1994. The official IGS products, namely orbits, ERPs, later on also the satellite clock corrections, were based on the contributions of the individual IGS Analysis Centers. So called "final" and "rapid" products were defined, produced and delivered. For a list of current IGS products, with accuracy and latentency information consult (Moore 2007). From the technical point of view the IGS Analysis Center Coordinator was responsible for regularly generating the IGS products in a timely manner. The IGS is proud of the fact that since 1 January 1994 (as a matter of fact already since 21 June 1992) this task was performed without failures and with increasing accuracy. This was of course only possible because

- the steadily growing IGS network of geodetic GPS receivers was reliable and of good quality,

- the data transmission based on the Internet was always available,

- the IGS concept of hierarchical data centers worked perfectly,

- the IGS Analysis Centers performed their computations in a timely fashion, and

- the orbit, ERP, and satellite clock comparison and combination strategies based on schemes proposed by Beutler et al. (1995) proved to be reliable and robust.
It was viewed as essential to make available to the user community reliable, robust and unique IGS products of highest quality within the promised time limits - in addition to the products of the individual analysis centers. The consistency of combined products is much more difficult to establish for a combination of analyses, which are based (at least partly) on the same observations, which estimate a common subset of parameters in addition to center-specific parameters, than the consistency of an individual analysis. In the latter case the consistency is, so to speak, guaranteed by the fact that all parameters are estimated in one and the same parameter estimation procedure. The IGS was very fortunate that its Analysis Center Coordinators Clyde Goad (IGS Test Campaign and Pilot Service 1992-1993), Jan Kouba (1994-1997), Tim Springer (1998-1999), Robert Weber (2000-2001), and Gerd Gendt (2002-2007) were extremely capable and experienced analysts. In December 2007 the IGS Governing Board elected Jim Ray from NOAA (National Oceanic and Atmospheric Administration) as the new IGS Analysis Coordinator.

Figure 2 documents the progress of the consistency of the individual solutions of IGS Analysis Centers (mean error per satellite coordinate) since 1993 . One can see that the consistency level of the IGS final products is of the order of $1-3 \mathrm{~cm}$ today. Compared to the consistency achieved in 1993 (see Table 3), more than an order of magnitude was gained. (The acronyms stand for COD CODE Analysis Center, GFZ: GeoForschungsZentrum, EMR: Energy, Mines and Resources, ESA: European Space Agency, JPL: Jet Propulsion Laboratory, MIT: Massachusetts Institute of Technology, NGS: National Geodetic Survey, SIO: Scripps Institute of Oceanography, and IGR: IGS Rapid orbit product.) The figure also underscores the importance of monitoring the products of the IGS Analysis Centers-quite 


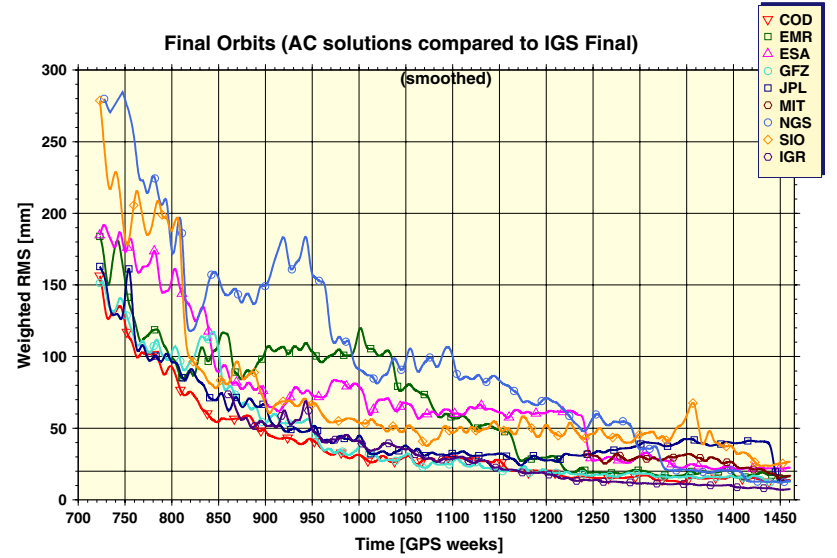

Fig. 2 Development of Orbit consistency since 1993 (root-meansquare errors per satellite coordinate of individual AC solutions with respect to the IGS final orbit, from GFZ homepage)

a few software "improvements" proved to be rather problematic.

These astonishing achievements were, of course, only possible thanks to a continuous refinement of the analysis methods and thanks to the continuous growth (densification) of the IGS Global Network, which consists today of well over 200 sites (see Fig. 3).

The IGS network is of paramount importance for geodynamics purposes. It is undoubtedly the most dense global realization of the ITRF, the International Terrestrial Reference Frame, as defined by the IERS. The ITRF is produced by the IERS using the results of all space geodetic techniques.

Similar statements can be made about the IGS ERPs: With their submilli-arc-second accuracy and their daily resolution of polar motion, the IGS significantly contributes to the monitoring of the ERPs. As a satellite geodetic service the IGS cannot contribute to other ERPs like Universal Time $U T 1$ or the parameters defining precession and nutation in an absolute sense. The IGS analyses are only sensitive to the time derivatives of these parameters during the time interval covered by an individual parameter estimation procedure (usually one to several days in the case of GNSS analyses).

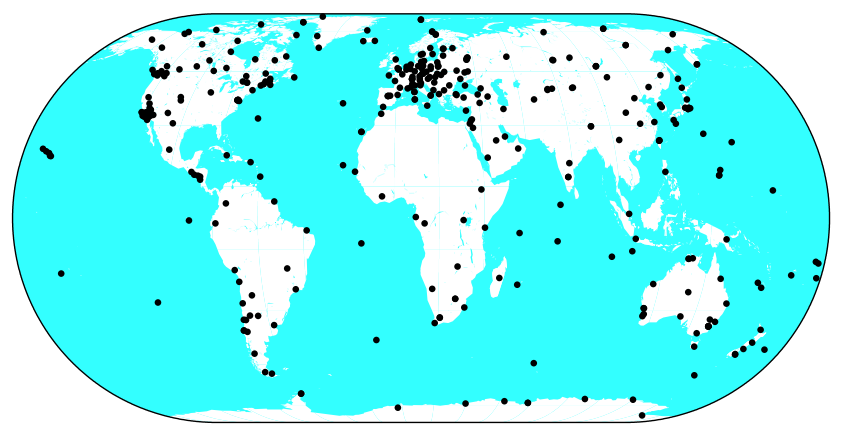

Fig. 3 IGS network January 2008
What was said so far about the development of the IGS might be characterized by the famous olympic ideal "altius, citius, fortius". One might thus get the impression that in 2008 the IGS does exactly the same things as in 1994, but in a much better way. This is of course true, it was, after all, the motivation for IAG to establish the service in 1993: The longterm perspective is a key element in the geodetic monitoring of the Earth. Monitoring Earth rotation has its roots in the late nineteenth century, when the ILS, the International Latitude Service, was created shortly before the end of the nineteenth century.

The IGS development has, however, yet another aspect: It developed into a multi-disciplinary service by extracting the maximum information from the permanent tracking activities performed within the IGS. Therefore, the IGS also might be called an "Interdisciplinary Service in Support of Earth Sciences" today. This aspect was in particular considered by Beutler et al. (1999). The IGS workshops, taking place at a rate of 1-2 per year, were extremely important in this respect. They are listed together with other important IGS events in Table 4.

Let us look at interdisciplinary aspects in more detail, where-in view of the limited space available-we will focus on a few aspects rather than on complete series of events and the sequence of their implementation within the IGS.

Whenever a new aspect was studied within the IGS, a so-called working group was created and the chairs of the working groups became members of the IGS Governing Board. The charters of these groups went (at least in some cases) far beyond the original charter of the IGS, which focused on the core products. The IGS extended its activities in particular into the following domains:

- Atmospheric research.

- Determination of LEO orbits.

- Time and frequency transfer using the GPS code and phase observable.

- Exploitation of the Russian GLONASS.

- Tide gauge projects.

- Development into the direction of a GNSS service.

The extension of the IGS to atmosphere sciences and to Low Earth Orbiting Satellites (LEOs) carrying GPS receivers was first discussed at the 1995 IGS Workshop in Potsdam (Gendt and Dick 1995), then at the 1996 (Neilan et al. 1996) and 1997 workshops (Neilan et al. 1997). Eventually, IGS LEO Working Group and the IGS Troposphere Combination Center were established in 1997 at the IGS Governing Board meeting at GFZ (GeoForschungsZentrum) in Potsdam.

The IGS Ionosphere Working Group was established in 1998. This was justified by the fact that ionosphere maps with a rather high temporal $(2 \mathrm{~h})$ and spatial resolution were 
Table 4 Selected IGS events (and events important for the IGS) 1994-present

\begin{tabular}{|c|c|}
\hline Date & Event \\
\hline January 1994 & Start of official service on January 1 \\
\hline November 1994 & Workshop on the Densification of the ITRF at JPL, Pasadena \\
\hline May 1995 & IGS Workshop on Special Topics and New Directions at GFZ in Potsdam \\
\hline March 1996 & IGS Analysis Center Workshop in Silver Spring, USA \\
\hline March 1997 & IGS Analysis Center Workshop at JPL in Pasadena \\
\hline December 1997 & IGS Retreat in San Francisco \\
\hline February 1998 & IGS Analysis Center Workshop at ESOC in Darmstadt \\
\hline December 1998 & Prof. Christopher Reigber elected as IGS Chairman 1999-2002 \\
\hline March 1999 & LEO Workshop, Potsdam, Germany \\
\hline June 1999 & Analysis Center Workshop, La Jolla, California \\
\hline March 2000 & IGS Tutorials in South Africa \\
\hline May 2000 & Selective Availability removed!! \\
\hline July 2000 & IGS Network Workshop \\
\hline July 2000 & Launch of CHAMP \\
\hline September 2000 & IGS Analysis Center Workshop at USNO, Washington \\
\hline December 2000 & IGS Strategic Planning Meeting \\
\hline February 2001 & LEO Workshop \\
\hline March 2001 & GLONASS Service Pilot Project \\
\hline March 2001 & TIGA (GPS Tide Gauge Benchmark Monitoring) Project established \\
\hline March 2002 & IGS Strategic Plan 2002-2007 published \\
\hline April 2002 & Ottawa Workshop: Towards Real-time \\
\hline July 2002 & UN Regional GNSS Workshop \\
\hline December 2002 & Prof. John Dow elected as IGS Chairman 2003-2006 \\
\hline April 2003 & Ionosphere maps (IONEX), etc., official IGS product \\
\hline May 2003 & First operational combined GPS/GLONASS analysis products \\
\hline August 2003 & Essential improvement of "near-real-time" orbits \\
\hline March 2004 & IGS Analysis Center Workshop and 10-year Symposium \\
\hline March 2005 & IGS renamed as International GNSS Service \\
\hline May 2006 & IGS Analysis Workshop at ESOC in Darmstadt, Germany \\
\hline December 2007 & Combined Space geodetic Analysis Workshop in San Francisco \\
\hline
\end{tabular}

created by some of the IGS Analysis Centers. It made thus sense to standardize, compare and combine the maps produced by different centers. Figure 4 shows an ionosphere map from January 2008 (near the minimum of solar activity).

The ionization of the Earth's upper atmosphere has now been monitored by the IGS for more than a full 11-year solar cycle. Figure 5 gives the daily mean total electron content (in a column of one square meter) for the time interval between 1995 and 2008. The dots are the observed values, the red curve approximates the measurements with a high time resolution, the blue curve is a heavily smoothed approximation, where apart from the 11-year cycle one essentially can see the annual and semi-annual periods. The high frequency part in the red curve is caused by the rotation of the Sun (with a period of about 27 days).

So far, only the "deterministic part" of the ionosphere (i.e., the part, which may be captured by ionosphere maps) was exploited by the IGS community. The "geometry free" linear combination of the carrier phases $L_{1}$ and $L_{2}$ also allow it to

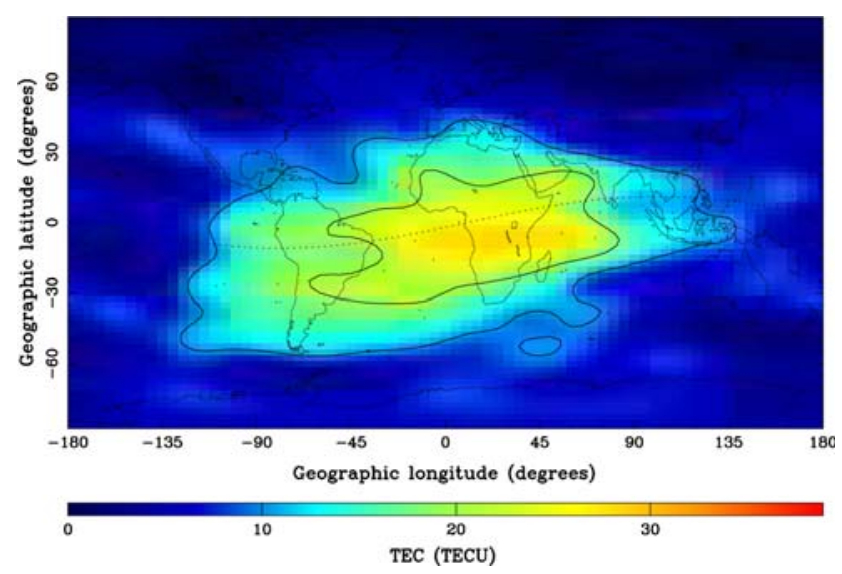

Fig. 4 Map of TEC (Total electron content on 8 January 2008) 


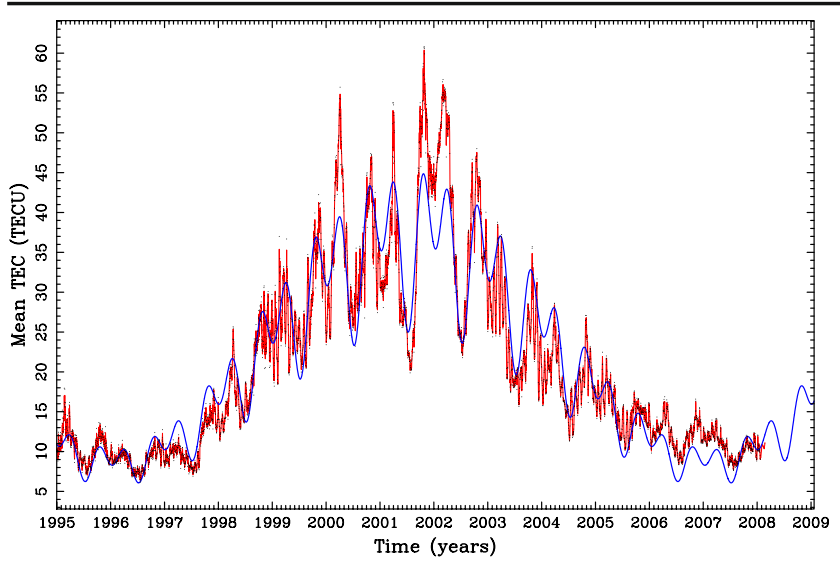

Fig. 5 Mean total ionosphere content per $\mathrm{m}^{2}$ (Mean TEC) between 1995 and 2008

extract information concerning the stochastic part, i.e., the rapid variations of ionospheric refraction in space and time. Given the global coverage of the IGS network (see Fig. 3) it should be possible to extract detailed statistical information concerning the ionization of the Earth's upper atmosphere.

At the 8th IGS Governing Board Meeting in December 1997 the IGS/BIPM Project to Study Accurate Time and Frequency Comparisons was created, where the IGS network is exploited (after previous suitable extension) for the purpose of high accuracy time and frequency transfer.

It is essential for a scientific service like the IGS to regularly analyze its activities and to make plans for the future. The development and publication of the IGS Strategic Plan (The IGS Governing Board 2002) was essential in this context. Two major goals were laid down for the years 2002-2007:

- The principal goal of the IGS is to provide a service to the international scientific community. However, IGS will seek to support a broader range of the Earth sciences by reaching out to non-solid-Earth scientific communities, including the atmospheric and ocean sciences. In addition, the recently enhanced recognition of the IGS as a key service of the International Association of Geodesy will assist in establishing the interdisciplinary links.

- As a secondary goal, the IGS will actively seek to serve society better by strengthening existing alliances and establishing new alliances and collaborations worldwide. In general, IGS will add value to its services and maintain the IGS products as the world standard.

\section{Key elements of the IGS}

The IGS is based on user requirements. Without the IGS each geodynamics group wishing to exploit the GPS or other GNSS for scientific purposes or each national mapping agency wishing to use GNSS for its first-order survey would have to generate its own GNSS satellite orbits-the orbits and the clock information broadcast by the system providers are clearly not sufficient for such purpose. A mixture (chaos) of local, regional, continental, etc., geodetic datums, but not a unique global terrestrial reference frame like the one represented by the ITRF would result. Thanks to the monitoring, comparison and combination procedures implemented by the IGS for its key products at a very early stage of its development, IGS products are easy to use and understand for a very broad class of users. Datum problems could be minimized.

The data transmission based on the internet is a key factor for the IGS. It proved to be extremely reliable. Before, let us say, 1990, data would have been stored on magnetic tapes or other rather inconvenient media and shipped using postal and/or courier services - a real nightmare for a service-like environment.

Redundancy of equipment and products is an important element of the IGS:

- The number of sites in the network is such that occasional receiver or data transmission failures are not (too much) harming the quality of the IGS products.

- The hierarchical/regional structure of the IGS data centers, and the maintenance of three global data centers make it comparatively easy to retrieve data with acceptable delay from anywhere on the globe. Loss of data did not occur, so far.

- The number of IGS Analysis Centers allows the Analysis Coordinator to detect and remove blunders from the IGS key products and to greatly reduce the effects of smaller inconsistencies in the official IGS products.

- There is no redundancy for the IGS Analysis Coordinator, for the IGS Central Bureau, and for the coordinators for the specialized products (like the ionsphere products) implying that these components are crucial for the proper functioning of the IGS.

The IGS is based on voluntary contributions of its participants, which means unfortunately also that there is no dedicated funding for IGS activities. With central funding it would, e.g., be much easier to create a perhaps less dense, but more homogeneous network than the one used today. On the other hand, thanks to the many cooperating institutions one is inclined to state that the IGS is statistically stable.

The IGS service is an interdisciplinary service supporting the fields of geodesy, geodynamics, atmosphere science, etc., an aspect which was extensively covered by Beutler et al. (1999).

With the full integration of GLONASS data and analysis with GPS operations in 2004, the IGS became a general GNSS Service. Links set up with the GALILEO system are a logical continuation of this process. 
Thanks to its performance in the past 15 years and thanks to the level of acceptance reached in the user community, the IGS has a good chance to maintain its position as the leading authority for the scientific exploitation of global navigation satellite systems for science and society. This is an extremely important aspect, because GNSS will be the work horses in space geodesy at least for the next 20-30 years.

Fifteen years of IGS operations cannot only consist of highlights. The following aspects are problematic and endanger the existence the IGS in its present form.

- Funding service-type operations is a problem in the science community. It is a big concern that quite a few of the IGS components are still financed by research and development funds. It is in particular getting more and more difficult for university-type and research institutions to raise the necessary funds to maintain their level of activities within the IGS.

- When compared to the original scope of the IGS, the activities were greatly expanded in the past. This growth, witnessed by the number of IGS working groups and pilot projects, had a significant impact on the work-load of some of the key components, in particular the IGS Analysis Coordinator and the IGS Central Bureau.

- The IGS does not have a business unit, allowing it to sign contracts with other organizations. This problem is known for a long time, but so far it could not be resolved in a satisfactory way.

- The IGS took over many responsibilities within geodesy, within the International Association of Geodesy in particular. This is of course fully justified by the huge impact of the GNSS on the entire field of geodesy. Problematic are the following aspects:

- Where is the borderline between service-like activities and pure research?

- How shall the interfaces be set up between the IGS on one hand and scientific units like the IAG Commissions, Study Groups, etc., on the other hand?

- How can the IGS stimulate scientific work, related to IGS activities, but outside the IGS?

- The IGS, in particular its Governing Board, carefully watched important new developments in the area of high-precision applications of GNSS. If a particular development seemed to be highly relevant to the development of the IGS, a working group or a pilot project was set up to address the issue. Often, such activities eventually became a success (e.g., time and frequency transfer using GNSS, GLONASS activities), sometimes the outcome was less convincing (e.g., in the case of the IGS involvement in the LEO (Low Earth Orbiters) analysis). Problems typically occurred when only few of the IGS components (in particular Analysis Centers or Associate Analysis Centers) participated in the projects or working groups or when the participation was based on insufficient manpower. It is impossible for the IGS Governing Board to enforce a high(er) level of activities to its voluntary contributors. The Board can and should, however, terminate IGS entities of this kind when it becomes clear that they cannot achieve the original goals.

\section{IGS, GGOS and IAG}

The IGS, together with the IERS pioneered the development of modern geodetic services in IAG. Their example was followed by the IVS (International VLBI Service for Geodesy and Astrometry), the ILRS (International Laser Ranging Service) and the IDS (International DORIS Service). These space-geodetic services, together with services related, e.g., to the determination of the Earth's gravity field or of the sea level, are of fundamental importance in modern geodesy and in the wider field of Earth sciences. They are part of a very precious global geodetic infrastructure.

This pioneer role of the IGS and the IERS, and their excellent record of activities and achievements, had a deep impact on the creation of the new structure of the IAG in the 1999-2003 time frame. As a consequence, the four IAG Commissions (on Reference Frames, on the Gravity Field, on Earth Rotation and Geodynamics, on Positioning and Application) and the IAG services are elements on the top level of the IAG structure.

The global geodetic infrastructure has more elements than just the services. The network of gravity sites, space geodetic missions like LAGEOS (LAser GEOdetic Satellite), CHAMP (CHAllenging Minisatellite Payload), GRACE (Gravity Recover And Climate Experiment), GOCE (Gravity field and steady-state Ocean Circulation Experiment), altimetry missions, and the network of analysis centers, are constituents of this infrastructure, as well. Unfortunately, this infrastructure is not on a stable "administrative" ground. We have seen major problems in recent years (mainly related to national funding) in the ILRS and the IVS.

Such developments and the insight that geodesy should study and monitor the system Earth as a whole, were the motivation for IAG to create the GGOS, which stands for "Global Geodetic Observing System". The term "system" should be understood as the basis on which the future advances in geosciences shall be built. By considering the Earth system as an entity (including solid Earth, atmosphere, ocean, hydrosphere, ice, liquid core, etc.), monitoring and studying it by geodetic techniques, the geodetic community does provide a powerful tool consisting mainly of high quality services, standards and references, and 
theoretical and observational innovations, to the global geosciences community. GGOS is based on the existing IAG Services and will provide the framework for existing or future services and ensure their long-term stability. GGOS was accepted as a new element ("flagship of IAG") of the IAG structure at the IUGG General Assembly in Perugia, Italy, in summer 2007. The IGS has played an active role in the development and implementation of GGOS. This system approach will have a major impact on the IGS work, it will in particular lead to a much closer cooperation between the IAG services.

It is legitimate to ask the question whether the IGS and the other IAG services benefit from the establishment of GGOS. As indicated above, the answer is affirmative from the technical point of view: A closer cooperation and coordination between services is mutually beneficial. Has GGOS the potential to improve the services' funding situation? It is more difficult to answer the latter question. It is, however, the GGOS vision that all major contributors to the global geodetic infrastructure sign up to the GGOS concept. Should this vision materialize, it would be logical for national funding agencies to bundle resources to the GGOS implementation. Should this development take place, all servicesincluding the IGS - would benefit tremendously from the GGOS development.

\section{Summary}

In 1992, the IGS essentially took off as an orbit determination service, focusing on the day-to-day determination of

- satellite ephemerides,

- GPS satellite clock corrections,

- Earth rotation parameters, in particular polar motion and length of day, and

- site coordinates.

There is an IGS product (or even a series of products) associated with each of the above items. The density of the global terrestrial network and the time resolution of the IGS products are unparalleled.

The following phases were distinguished in the development of the IGS:

- Planning phase 1989-1991.

- Proof of concept phase 1992.

- Pilot service 1992-1993.

- Official IAG service since 1 January 1994.

In the years 1994-1998 the IGS developed into an interdisciplinary service in fields of geodesy, geodynamics, Earth sciences and fundamental astronomy by considering the following topics:
- Global ionosphere mapping.

- Troposphere mapping over the IGS sites (determination of water vapor content).

- Time and frequency transfer between timing laboratories.

- Kinematic and deterministic determination of LEO orbits based on the IGS products.

By conducting dedicated GLONASS observation (and analysis) campaigns in the late 1990s and by eventually issuing GLONASS ephemerides as official IGS products in 2004, the IGS developed into a general GNSS (Global Navigation Satellite Systems) service. This development shall be further pursued by implementing at the earliest possible stage the geodetic measurements generated by the GALILEO system into the IGS strategy.

The IGS claims to be the authority concerning the scientific exploitation of all GNSS. The IGS and the other services are the building blocks of GGOS and an important part of the global geodetic infrastructure developed and deployed in the twentieth century. It is our duty to secure this infrastructure and to make the best use of it to monitor the Earth with its constituents.

Acknowledgments The contributions of the IGS network to the scientific community are fundamentally due to the diligent effort of the many site operators worldwide. Likewise, the development of IGS' geodetic products is thanks to personnel at each analysis center. The long-term success of the IGS is a credit to the Governing Board members, product coordinators, and Central Bureau management past and present. A. Moore's work was carried out at the Jet Propulsion Laboratory, California Institute of Technology, under a contract with the National Aeronautics and Space Administration.

\section{References}

Beutler G, Bauersima I, Gurtner W, Rothacher M, Schildknecht T (1987) Evaluation of the 1984 Alaska Global Positioning System Campaign with the Bernese GPS Software. J Geophys Res (USA) 92:1295

Beutler G, Brockmann E (eds) (1993) Proceedings of the 1993 IGS Workshop. Printing Office, University of Bern

Beutler G, Mueller II, Neilan RE (1994) The International GPS Service for Geodynamics (IGS): Development and Start of Official Service on 1 January 1994. Bull Geodesique 68(1):43-46

Beutler G, Kouba J, Springer T (1995) Combining the orbits of IGS processing centers. Bull Géodésique 69:200-222

Beutler G, Mueller II, Neilan RE (1996) The International GPS Service for Geodynamics (IGS): The Story, International Association of Geodesy Symposia 115. In: Beutler G, Hein G, Melbourne W, Seeber G (eds) GPS Trends in Precise Terrestrial, Airborne and Spaceborne Applications. Springer, Heidelberg, pp 3-13

Beutler G, Rothacher M, Schaer S, Springer TA, Kouba J, Neilan R (1999) The International GPS Service (IGS): an interdisciplinary service in support of Earth sciences. Adv Space Res 23:631-653

Boucher C, Altamimi Z (1993) Contribution of IGS 92 to the Terrestrial Reference frame. In: Proceedings of the 1993 IGS Workshop, Printing Office, University of Bern 
Gendt G, Dick G (1995) Special Topics and New Directions. In: Proceedings of IGS Workshop 15-18 May, Potsdam, Germany

Kouba J (ed) (1993) IGS Analysis Center Workshop 12-14 October 1993, Geodetic Survey Division, Natural Resources Canada, Ottawa, Canada

Melbourne WG, Fisher SS, Neilan RE, Yunck TP, Engen B, Reigber Ch, Tatevjan S (1993) The first GPS IERS and Geodynamics Experiment-1991. In: Mader G (ed) Permanent Satellite Tracking Networks for Geodesy and Geodynamics, IAG Symposium 109. Springer, Berlin

Moore AW (2007) IGS network: Application of GPS to geodesy. Indian J Radio Space Phys 36:261-267

Mueller II (1990) Satellite Positioning and the IAG, keynote address. In: Proceedings 2nd International Symposium on Precise Positioning with the Global Positioning System-GPS '90, pp XLVIII-LXVI, The Canadian Institute of Surveying and Mapping, Ottawa K2C $3 \mathrm{~J} 1$

Mueller II (1992a) Planning an International Service using the Global Positioning System (GPS) for Geodynamic Applications. In: Procceedings of the International Association of Geodesy on Permanent Satellite Tracking Networks for Geodesy and Geodynamics, IAG Symposium 109. Springer, Berlin, pp 1-22

Mueller II (1992b) The Role of the International Association of Geodesy in Establishing User Services. In: Reigber C, Montag H (eds) IAG Symposium 112, Geodesy and Physics of the Earth, 1993. Springer, Berlin, pp 3-4

Mueller II, Beutler G (1992) The International GPS Service for Geodynamics-Development and Current Structure. In: Kumar M, Fell P (eds) Proceedings of the 6th Symposium on Satellite Positioning. The Ohio State University, Columbus, Ohio, pp 823-835

Mueller II (1993a) The International GPS Service for Geodynamics (IGS) and the Terrestrial Reference Frame. In: Mueller II,
Kolaczek B (eds) International Astronomical Union Symposium No. 156: Developments in Astrometry and Their Impact on Astrophysics and Geodynamics. Kluwer, Dordrecht, p 405

Mueller II (1993b) The International GPS Service for Geodynamics: an Introduction. Beutler G, Brockman E (eds) Proceedings 1993 IGS Workshop, Bern. Printing Office, University of Bern, pp 1-2

Mueller II (1993c) The International GPS Service for Geodynamics: Terms of Reference. In: Beutler G, Brockman E (eds) Proceedings 1993 IGS Workshop, Bern. Printing Office, University of Bern, pp $11-18$

Mueller II (1993d) The IGS Polyhedron: Fiducial Sites and Their Significance. In: Beutler G, Brockman E (eds) Proceedings 1993 IGS Workshop, Bern. Printing Office, University of Bern, pp 76-81

Neilan RE, Dixon TH, Meehan TK, Melbourne WG, Scheid JA, Kellogg JN, Stowell JL (1989) Operational Aspects of CASA UNO '88-The first large scale International GPS Geodetic Network, IEEE Trans Instr Meas (US), 38 (1989) pp 648ff

Neilan RE, Melbourne W, Mader G (1990) The Development of a Global GPS Tracking System in Support of Space and Groundbased GPS Programs, In: Bock Y, Leppard N (eds) Global Positioning System: an Overview, IAG Symposium 102. Springer, Berlin, pp 165-178

Neilan RE, Van Scoy PA, Zumberge JF (eds) (1996) 1996 IGS Analysis Center Workshop, 19-21 March 1996, Silver Spring, Maryland, USA

Neilan RE, Van Scoy PA, Woodworth PL (eds) (1997) Workshop on Methods for Monitoring Sea Level, 19-21 March 1996, Jet Propulsion Laboratory, Pasadena, USA

The IGS Governing Board (2002) IGS Strategic Plan 2002-2007, Jet Propulsion Laboratory, Pasadena, USA, JPL 400-1000 03/02 